Port Acadie

Revue interdisciplinaire en études acadiennes

An Interdisciplinary Review in Acadian Studies

\title{
Groupe de recherche en patrimoine religieux acadien
}

\section{Nicolas Landry}

Numéro 18-19, automne 2010, printemps 2011

URI : https://id.erudit.org/iderudit/1010307ar

DOI : https://doi.org/10.7202/1010307ar

Aller au sommaire du numéro

Éditeur(s)

Université Sainte-Anne

ISSN

1498-7651 (imprimé)

1916-7334 (numérique)

Découvrir la revue

Citer cette note

Landry, N. (2010). Groupe de recherche en patrimoine religieux acadien. Port Acadie, (18-19), 175-177. https://doi.org/10.7202/1010307ar d'utilisation que vous pouvez consulter en ligne. 


\title{
Groupe de recherche en patrimoine religieux acadien
}

\author{
Nicolas Landry \\ Université de Moncton (campus \\ de Shippagan)
}

À une époque où le patrimoine religieux à la fois bâti et institutionnel se voit confronté à d'énormes défis financiers, organisationnels et patrimoniaux, qui ont déjà conduit à des disparitions ou des transformations, les historiens interrogent de plus en plus le passé de ces institutions dont la mémoire est menacée. Prenons pour exemples les travaux effectués à l'Université Sainte-Anne de Pointe-de-l'Église, en Nouvelle-Écosse ${ }^{1}$, et ceux de la Chaire de recherche du Canada en patrimoine urbain de l'Université du Québec à Montréal' ${ }^{2}$. Ces préoccupations envers l'œuvre religieuse, économique et éducative des communautés religieuses ayant œuvré au nord du Nouveau-Brunswick suscitent l'intérêt d'un nouveau groupe de recherche récemment formé à l'Université de Moncton, campus de Shippagan, soit le Groupe de recherche en patrimoine religieux acadien de l'UMCS.

En réalité, les travaux préliminaires du groupe remontent à 2008 avec la mise en chantier du livre commémoratif soulignant le $50^{\mathrm{e}}$ anniversaire (2010) de l'UMCS. Or, les deux premiers chapitres de cet ouvrage soulignent précisément l'œuvre éducatrice des religieuses de JésusMarie avec l'implantation du Couvent Jésus-Marie (1948) et ensuite du Collège Jésus-Marie (1960) à Shippagan. Les professeurs Nicolas Landry et Florence Ott se sont associés dans ces travaux et ce partenariat a mené à un deuxième projet commémoratif, soit le $100^{\mathrm{e}}$ anniversaire de l'Académie Sainte-Famille de Tracadie-Sheila (2012). Par la même occasion, un troisième membre s'est greffé au groupe, soit monsieur Philippe Basque, historien au Village acadien de Caraquet. Monsieur Basque s'intéresse

1. Voir entre autres les travaux du Groupe de recherche en études acadiennes et de la Chaire de recherche du Canada en oralité des francophones minoritaires d'Amérique (CofRAm) : Le Patrimoine religieux de la Nouvelle-Écosse. Signes et paradoxes en Acadie, Actes du colloque organisé les 19 et 20 juin 2006 à l'Université SainteAnne, dans Port-Acadie. Revue interdisciplinaire en études acadiennes, $n^{\circ \mathrm{s}} 10-11-$ 12, automne 2006 - printemps 2007 - automne 2007, Université Sainte-Anne, $315 \mathrm{p}$.

2. Cette chaire est dirigée par Luc Noppen. 
tout particulièrement à la conservation du patrimoine religieux bâti dans les communautés francophones des Maritimes. Il a notamment collaboré avec madame Florence Ott sur la valorisation de fonds documentaires, photographiques et archivistiques de la Société historique Nicolas-Denys, ainsi que du Village historique acadien. Le professeur d'histoire Nicole Lang de l'Université de Moncton (campus d'Edmundston) a accepté de se joindre au groupe à l'occasion d'activités ponctuelles portant sur l'œuvre des communautés religieuses en éducation et en santé au nord-ouest du Nouveau-Brunswick. Pour sa part, l'historien Allen Doiron est archiviste aux Archives provinciales du Nouveau-Brunswick à Frédéricton et s'intéresse aux traces écrites et aux dépôts d'archives et d'objets muséaux laissés par les congrégations religieuses en Acadie.

Il est à noter que le Groupe de recherche en patrimoine religieux acadien de l'UMCS ne se limitera pas au livre comme seul outil de diffusion. Il aura également recours aux médias électroniques, à des conférences publiques et à des participations à des colloques scientifiques. Les activités du groupe ont d'ailleurs déjà suscité l'intérêt d'un groupe de recherche de l'Université d'Ottawa, dirigé par la linguiste France Martineau et dont le projet s'intitule le français à la mesure d'un continent. II pourrait en résulter un nouveau projet portant sur les spécificités historiques de la communauté francophone de Caraquet depuis 1870.

Dans l'optique d'assurer une certaine résonance des travaux du groupe à la fois dans la communauté universitaire et auprès du public, des partenaires importants sont à mentionner, soit l'UMCS, le Centre de documentation historique Nicolas-Denys, le Village historique acadien et l'Association des anciens et amis de l'Académie Sainte-Famille de Tracadie-Sheila.

Le groupe a déjà prévu une première participation à un colloque scientifique. En effet, trois de ses membres présenteront des communications à une séance du congrès annuel de la Société historique du

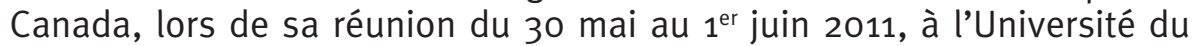
Nouveau-Brunswick, à Frédéricton : Nicolas Landry, "Commémoration de l'œuvre des religieuses Jésus-Marie à Shippagan, 1948-1975 "; Florence Ott, "Commémoration de la construction de l'Académie Sainte-Famille à Tracadie par les religieuses hospitalières Saint-Joseph, 1912-2012 "; Philippe Basque, « Les lieux historiques religieux du nord-est du NouveauBrunswick : quelle mémoire en conserve-t-on?».

Deux projets de publication sont aussi en cours : un livre commémoratif portant sur le $50^{\mathrm{e}}$ anniversaire de l'Université de Moncton (campus de Shippagan), dans lequel on relate la contribution inestimable de la congrégation Jésus-Marie à l'avènement de cette institution dans la région (à paraître en 2011); et un livre commémoratif portant sur le $100^{\mathrm{e}}$ 
anniversaire de l'Académie Sainte-Famille de Tracadie et la congrégation des religieuses hospitalières de Saint-Joseph (à paraître en 2012). 